\title{
Deafferentation in monkeys: Extinction of avoidance responses, discrimination and discrimination reversal'
}

\author{
EDWARD TAUB, DANIEL TEODORU, STEVEN J. ELLMAN, RICHARD F. BLOOM AND A. J. BERMAN \\ ISAAC ALBERT RESEARCH INSTITUTE, JEWISH CHRONIC DISEASE HOSPITAL, BROOKLYN, N. Y.
}

The surgical abolition of sensation from the forelimbs of rhesus monkeys was found to produce a pronounced retardation in the rate of extinction of a trace forearm flexion CAR when view of the limbs was precluded. In an attempt to ascertain the mechanism underlying this phenomenon groups of normal and deafferented $S s$ were subjected to different extinction procedures in which the amount of available information concerning the response was varied. Intact and operated Ss were also compared with respect to rate of leaming a "gono go" auditory discrimination and a discrimination reversal.

Previous experiments from this laboratory have demonstrated that the surgical abolition of sensation from a monkey's forelimbs does not prevent extensive learning and performance of purposive movement under a wide variety of circumstances (Knapp, Taub, \& Berman, 1958, 1963; Taub, Bossom, \& Berman, 1965; Taub, Ellman, \& Berman, in press). However, as might be expected, sensory denervation is by no means without effect. For example, it was found that deafferentation of either one or both upper extremities results in a retardation of the rate of acquisition of a forelimb flexion trace-conditioned avoidance response (CAR) by a factor of approximately three (Taub \& Berman, 1963, 1964; Taub, Bacon, \& Berman, 1965). The purpose of the present study was to examine the effect of limb deafferentation on the extinction of a trace CAR.

Method

Six rhesus monkeys with intradural deafferentation of both forelimbs (C2-T3) and five normal monkeys were conditioned in a trace avoidance situation identical to that employed in previous studies. The CS was a click, the CS-US interval was $3-1 / 2$ sec., and in the absence of a right forelimb flexion between a lamp and photoelectric receiver located 5 in. above a board upon which the arm normally rested, shock was delivered to the left ear of the seated $S$ for an additional $3-1 / 2$ sec. During training the limbs could not be seen. Twenty trials were given each session with a mean intertrial interval of $75 \mathrm{sec}$. After reaching a minimum acquisition criterion of $80 \%$ on two consecutive days, two Ss from each group were given five additional conditioning sessions. The remaining animals were overtrained for 30 days. During this period it was required that a stringent stability criterion be maintained. Following overtraining an extinction series was begun and continued till a criterion of $80 \%$ no-response for one session was reached.

Subsequently, four additional groups were added to the study. For all these Ss the CSduring acquisition was a response terminable buzzer. After the usual learning criterion had been reached there followed 30 overtraining days. For four normal and three deafferented monkeys the procedure was changed during extinction; the buzzer could not be terminated and thus always continued for a full $7 \mathrm{sec}$. One might say that these animals were being informed that the CR was no longer effective. Therefore, these were viewed as "Correct Information" (CI) Groups. The remaining Ss, two normals and one deafferent, were allowed to continue terminating the buzzer during extinction, thereby receiving secondary reinforcement even though the primary negative stimulus would not have been delivered if the CR were not made. This was viewed as a "False Information" (FI) situation. The original click, traceconditioned Ss were considered, within this paradigm, to constitute "No Information" (NI) Groups.

Since extinction phenomena are presumably involved in learning a "go-no go" discrimination and especially a discrimination reversal, the next phase of the investigation was undertaken in an attempt to determine whether there is a difference between normals and deafferents in this respect. Following extinction, all buzzer Ss were reconditioned. There was no difference in the rates at which normals and deafferents reached acquisition criterion. A pure tone, $\mathrm{CS}^{-}$, was then introduced on half the trials in random order. On the buzzer trials the task for $\mathrm{S}$ remained the same. If a response was emitted within 3-1/2 sec. after CSonset, shock was avoided. On the tone trials, however, $S$ was required to not respond. The CS could not be terminated and each time the photoelectric beam was interrupted a brief but intense shock was delivered to the left leg. After a criterion of $80 \%$ correct response on both buzzer and tone trials hadbeen reached on two consecutive days, the reinforcement contingencies were reversed. The Ss now had to respond to the tone but not to the buzzer in order to avoid shock. Results

Table 1 contains a summary of all the data from the present experiment. The upper portion of the table indicates that the extinction of a trace CAR proceeded 4.5 times more slowly for deafferents than for normals ( $p<.05, U$ test); approximately the same factor by which acquisition was retarded. The "Correct Information" procedure speeded extinction for both types of $S$, but to a much greater extent for deafferents, who thus extinguished as rapidly as did the normals. The ratio of the difference in rates of extinction between "No 
Table 1. Mean Days Prior to Reaching Extinction, Discrimination and Discrimination Reversal Criteria for All Deafferented and Intact Groups $^{a}$

\begin{tabular}{llclc} 
Group & $\mathrm{n}$ & Deafferented & $\mathbf{n}$ & Intact \\
\hline NI Click & $6^{b}$ & 56.0 & $5^{b}$ & 12.4 \\
Cl Buzzer-nonterm. & 3 & 2.7 & 4 & 2.8 \\
Fl Buzzer-term. & 1 & 89 & 2 & 51.0 \\
Discrim. & 4 & 2.3 & 6 & 5.7 \\
Discrim. Reversal & 2 & 23.5 & 4 & 12.7 \\
\hline
\end{tabular}

a Criterial days are not included in these figures.

$b$ Two Ss were given 5 days of overtraining: the others 30 days.

Information" and "Correct Information" Groups for normals was approximately 4 , but for deafferents it was 21. The ratios differ by a factor of approximately 5 . (Results from the "False Information" Groups are, as yet, too scanty to provide a basis for interpretation.)

The discrimination and discrimination reversal results are summarized at the bottom of Table 1. Of most significance here is the fact that deafferents were able to learn the discrimination and in the two cases tested to date, the discrimination reversal. Surprisingly, normals and deafferents did not differ significantly (p>.05, $U$ test) in the number of days that were required to achieve criterial performance on the discrimination. However, it may be that these data are contaminated by a possible differential tendency between normals and deafferents to generalize from buzzer to tone. Thus, it would probably be more valid to compare the results from the discrimination reversal situation where this problem does not arise; but they are, at present, insufficient for this purpose.

\section{Discussion}

The initial data in this study were collected from the trace-conditioned groups. Two hypotheses were considered as possible explanations for the observed increase in the resistance to extinction of the deafferented Ss. An 'Information Hypothesis" ' was based on the fact that deafferented monkeys would have less information concerning the nature of movements of an unseen extremity than would intact Ss. Thus, for example, accidental performance of non-avoidant movements, which should hasten the process of extinction, would not be as readily discriminated by deafferents as by normals. This notion will be recognized as being closely related to the Generalization Decrement Theory of Extinction. Alternately, it was considered possible that the prolonged period required for the extinction of the trace CAR in deafferents was due to the wellknown supersensitivity that develops in deafferented spinal motoneurons (Teasdall \& Stavraky, 1953). Thus, Ss with a deafferented limb might have been less able to inhibit well-learned CRs of that extremity than intact Ss. This hypothesis may be viewed as a type of indirect application of the Inhibition Theory of Extinction to the present experimental situation.

In order to determine which of the two hypotheses constitutes a more appropriate interpretation of the trace CAR data, the two "Correct Information" Groups were added to the study. Our reasoning was that if the "Information Principle" is of greater significance than the "Excitation Principle," then an increase in information ought to have a much more profound effect on the rate of extinction of the deafferents than of the normals. The results provide support for the "Information Hypothesis," at least insofar as it applies to the present study. By supplying additional, though "indirect," information concerning the CR to deafferented $\mathrm{Ss}$, their resistance to extinction became no different from that of normal Ss similarly treated. In general, we might say that the more information that deafferents have concerning unseen movements, the more similar their behavior becomes to that of normals.

In the present situation, then, information was clearly an extremely powerful variable in the control of behavior. A reinforcement theory could explain very simply the differences within the deafferented groups or within the normal groups. But in order to account for the differences between the normal and deafferented groups, informational concepts would have to be added to the formulation.

The fact that monkeys can be trained to respond differentially to two related stimuli with an unseen limb from which senation has been eliminated, and then learn to reverse the pattern of response should be remarked. This conditioned behavior is more complex in certain respects than any noted in earlier deafferentation experiments from this laboratory. We thus have additional confirmation here for our previously stated view that the primate CNS is capable of a great deal more autonomy and independence from the periphery in the acquisition and maintenance of behavior than has generally been thought possible.

\section{References}

Knapp, H. D., Taub, E., \& Berman, A. J. Effect of deafferentation on \& conditioned avoidance response. Science, 1958, 128, 842843.

Knapp, H. D., Taub, E., \& Berman, A. J. Movements in monkeys with deafferented forelimbs. Exp. Neurol., 1963, 7, 305-315.

Taub, E., Bacon, R. C., \& Berman, A. J. Acquisition of a traceconditioned avoidance response after deafferentation of the responding limb. J. comp. physiol. Psychol., 1965, 59, 275-279.

Taub, E., \& Berman, A. J. Avoidance conditioning in the absence of relevant proprioceptive and exteroceptive feedback. J. comp. physiol. Psychol., 1963, 56, 1012-1016.

Taub, E., \& Berman, A. J. The effect of massive somatic deafferentation on behavior and wakefulness in monkeys. Paper presented at Psychonomic Society Meeting, Niagara Falls, Ont., October 1964.

Taub, E., Bossom, J., \& Berman, A. J. Adaptation of reaching behavior to prismatic displacement of vision in deafferented monkeys. Paper presented at Conference on Adaptation to Rearrangement, Massachusetts Institute of Technology, June 1965.

Taub, E., Ellman, S. J., \& Berman, A. J. Deafferentation in monkeys: effect on conditioned grasp response. Science, in press.

Teasdall, R. D., \& Stavraky, G. W. Responses of deafferented spinal neurons to corticospinal impulses. J. Neurophysiol., 1953, $16,367-375$

\section{Note}

1. This research was supported by PHS Grant NB-3045. The surgical assistance of Mr. Gilbert Barro and the technical assistance of Mr. Arnold Benjamin are gratefully acknowledged. 